\title{
Depressive disorder in academic and family structure in Vietnamese adolescents
}

\author{
Research Article
}

\section{Be Thi Ngoc Nguyen ${ }^{*}$, Hung Thanh Nguyen²}

\author{
1. Department of Psychology and Education, University of Education, Hue University, 34 Le Loi Street, \\ Phu Hoi Ward, Hue City, Thua Thien Hue Province, Vietnam. \\ 2. Department of Psychology and Education, University of Education, Hue University, 34 Le Loi Street, \\ Phu Hoi Ward, Hue City, Thua Thien Hue Province, Vietnam.
}

\begin{abstract}
The symptoms of depression are related to low academic achievement, suicidal ideation and cause emotional sufferings, fundamental impairments which can influence students' abilities to perform essential activities of daily living. This study conducted to examine the relationships between depression and not only academic performance but also family structure. This study used the Beck Depression Inventory-II to survey 1336 students from secondary and high schools in Hue province, Vietnam. The findings of our study showed that there were associations between levels of depression and academic performance. Students with good or excellent academic performance were more likely to increase depression than others. Besides, students who had divorced or separated parents were more likely to increase depression gradually than the others. Context: The symptoms of depression are related to low academic achievement, suicidal ideation and cause emotional sufferings, fundamental impairments which can influence students' abilities to perform essential activities of daily living. Aims: This study conducted to examine the relationships between depression and not only academic performance but also family structure. Methods and Material: This study used the Beck Depression Inventory-II to survey 1336 students from secondary and high schools in Hue province, Vietnam. Results: The findings of our study showed that there were associations between levels of depression and academic performance. Conclusions: Students with good or excellent academic performance were more likely to increase depression than others. Besides, students who had divorced or separated parents were more likely to increase depression gradually than the others.
\end{abstract}

Key Words: Student, Depression, Family structure, Academic performance, GPA.

\section{Introduction}

Depression is a widespread phenomenon (1). It is one of the most important mental health problems which has been globally documented by children and adolescents in numerous countries including Australia, India, Greece, Russia, and China (2-5). The primary causes of depression are adverse life events, hopelessness, helplessness, and disease. The prevalence of depression is from $3 \%$ to $15 \%$ of the general population in which the cases seriously affected have $0.4-5 \%$. Specifically, depression affects preschool children at $0.3 \%$, school children at $2 \%$ and adolescents from 10 to 19 years old at $4-8 \%$ in young people (6). It has been recognized by psychologists that depression is common not only in adults but also in children and adolescents, especially in secondary and high school students. The symptoms of depression cause emotional sufferings and fundamental impairments, which can influence students' abilities to perform essential

\section{* Corresponding Author:}

\section{Be Thi Ngoc Nguyen}

Department of Psychology and Education,

University of Education, Hue University,

34 Le Loi Street, Phu Hoi Ward, Hue City,

Thua Thien Hue Province, Vietnam.

Email Id: ntngocbe@hueuni.edu.vn activities of daily living such as participating in social activities, maintaining balance in ongoing relationships (7-9) or resolving potential disharmony at home (10), and are related to low academic achievement, social dysfunction, and suicidal ideation and behaviour (11). The negative impact of depression is also presented with social isolation and substance abuse (6). Depressed children and adolescent often face academic concerns including lack of energy, motivation and hopes to study and succeed in the school, a decrease of concentration and focus in studying process in the classroom $(12,13)$ which lead to poor academic performance (14). Besides, several researchers reported that experiencing school difficulties and problems were one of the main causes of growing depression among adolescents $(12,13,15)$. Depressed children and adolescents frequently face general co-occurring issues which are low academic achievement, school attendance problems, school failure (16) and academic pressure including the rising amount of schoolwork, assignment deadlines, and school examinations (17).

The influences of depression on students have been mentioned in numerous scientific researches for a long time. Khesht-Masjedi, Shokrgozar (18) revealed that depression had a negative effect on academic achievement among teenagers. Students with depressive symptoms would decrease motivation in concentration and paying attention to learn, which led to a decrease in 
academic achievement. Besides, several studies investigated the correlation between depression and academic performance. Busari (19) evaluated and reported a significant and negative correlation between depression and academic performance. This result is directly in line with Owens, Stevenson (20), which surveyed numerous developing UK students from 12 to 13-years-old. They investigated the relationship between depression and academic performance and indicated that the higher levels of depression students had a lower academic performance. According to the findings in the research conducted in Santiago, Chile which surveyed 894 adolescents from 12 to 17 years old and emphasized the influences of mental health on educational outcomes, depressive symptoms caused adolescents not to perform well as they expected in studying process in school (21). These findings are in accordance with findings reported by Shippee and Owens (22), which suggested that depression had a negative effect on achievement outcomes throughout high school. Moreover, the results of the previous studies reported by Lewinsohn, Roberts (23) and Roeser, Eccles (24) also revealed that there was an association between low-grade point average (GPA) and high level of depression in the adolescent. These findings are directly in line with previous findings of Brubeck and Beer (25), which indicated that students displaying a high level of depression had lower grade point averages than did the others.

On the contrary, Chen and Li (26) showed no association between academic achievement and adolescent depression. The findings suggest that studying process in schools such as many assignments, overwhelming contents, or difficulties in completing homework required to maintain attention and concentration caused depression in Chinese students. Besides, Shahar, Henrich (27) revealed that with high levels of depression, there were adverse influences of self-criticism on boys' GPA.

Academic achievement and family structure have been mentioned in numerous scientific research on the factors affecting students' depression. Brubeck \& Brubeck and Beer (25) surveyed 131 Kansas high school students with background information and the Beck Depression Scale. The researchers concluded that students from divorced families suffered more depression than students living with both parents. They also reported that children from divorced parents had lower grade point averages and self-esteem than children from intact families. Rodgers (28) also revealed that daughters following parental divorce showed high levels of depression in a longitudinal study. Besides, Lloyd (29) indicated that experiencing parental bereavement during childhood increases the risk of depression in adulthood. Children from divorced families had more adverse experiences in daily life compared to children from intact families (30) and had to face many emotional difficulties such as the disturbance in self-control and aggressiveness and lowered self-esteem (31-33). These findings suggested that family factors had significant effects on students' depression, especially family structure.
The transformation of family structure causes childhood family instability which has enduring negative influences on psychological wellbeing (34). Specifically, the change from a biological parent family to single-mother family or cohabiting stepfamily has been increased the probability for depression in adolescents with an average age of 15-years (34). With the transformation of family structure in our society still ongoing, it is necessary to examine the influences of family transition on children's mental health. Many scientific researchers reported that adolescents living in a single-parent family suffered more commonly from depression than adolescents living in a two-parent family (35-38). This result supports previous conducted by Feldman, Rubenstein (39). The researchers surveyed 103 unselected sixth-grade students and indicated significant correlations between family structure and depressive affect. They reported that students from single-parent families background showed more depression than those from intact families' backgrounds.

Furthermore, if young adolescents felt less cohesive, less adaptable from their families, or there were problems in the communication between them and parents, they would suffer more depressive symptoms. Laukkanen, Hakko (40) examined 508 adolescent inpatients who suffered severe mental disorders, aged from 15 to 17 years old, and treated in the psychiatric hospital between April 2001 and March 2006. They concluded that adolescents suffered depressive symptoms and admitted that psychiatric treatment was more usually from a single-parent family background which is a statistically significant predictor that doubled the risk for depression in adolescents. Besides, Sadock and Sadock (41) reported that students living with both parents had a lower rate of depression than those from other backgrounds. Moreover, parental bereavement or divorce commonly destroys mental health and emotions of children. For several purposes, school advisors must have the skills required to identify, assist and refer troubled adolescent students (42).

Depression of students is not a new topic. However, few studies have focused on this subject in Vietnam, especially the relationship between depression and GPA or family structure. To fill this gap, we examine the associations between depression and GPA and family structure that influence students' depression. The research reviews the literature on the relationship between students' depression and academic achievements and family structure. In the second section, a basic analytical framework is described, including the research methodology, result, and discussion. Finally, the conclusion is in the last section.

\section{Methods \\ Participants}

Participants were selected randomly from five schools in Thua Thien Hue province, Vietnam. All participants provided informed consent after receiving an explanation of the purpose of the research. The survey instrument distributed to 1351 Vietnamese participants, of which 1336 questionnaires 
returned, for a 98.89 percent return rate, which exceeds the 30 percent response rate most researchers require for analysis (43). The students participated in this prospective study from January 2019 to December 2020. The sample of this study was drawn from 1336 students who completed the survey instrument. There were more Two-parent family $(88.5 \%)$ Divorced or separated parents $(6 \%)$ and Deceased father/mother (3.7\%) among the 1336 Vietnamese students who surveyed.

Table 1. An overview of survey participants

\begin{tabular}{|c|c|c|c|}
\hline & & n & $\%$ \\
\hline \multirow{3}{*}{ Gender } & Male & 613 & 45.9 \\
\hline & Female & 718 & 53.7 \\
\hline & LGBT & 5 & 0.4 \\
\hline \multirow{5}{*}{ Schools } & $\begin{array}{l}\text { Nguyen Tri Phuong } \\
\text { secondary school }\end{array}$ & 342 & 25.6 \\
\hline & $\begin{array}{l}\text { Thong Nhat secondary } \\
\text { school }\end{array}$ & 370 & 27.7 \\
\hline & Gia Hoi high school & 233 & 17.4 \\
\hline & $\begin{array}{l}\text { Quoc Hoc high school for } \\
\text { the Gifted }\end{array}$ & 177 & 13.2 \\
\hline & $\begin{array}{l}\text { Dang Tran Con high } \\
\text { school }\end{array}$ & 214 & 16.0 \\
\hline \multirow{4}{*}{$\begin{array}{l}\text { Family } \\
\text { structure }\end{array}$} & Two-parent family & 1182 & 88.5 \\
\hline & $\begin{array}{l}\text { Divorced or separated } \\
\text { parents }\end{array}$ & 80 & 6.0 \\
\hline & Deceased father/mother & 50 & 3.7 \\
\hline & Another situation & 24 & 1.8 \\
\hline Acade & Poor & 3 & 0.2 \\
\hline performance & Below average & 30 & 2.2 \\
\hline (Grade point & Average & 277 & 20.7 \\
\hline average, & Good & 565 & 42.3 \\
\hline GPA & Excellent & 461 & 34.5 \\
\hline
\end{tabular}

Note: $\mathrm{n}$ : Number of participants; \%: Percentage

\section{Measure}

This study used the Beck Depression InventoryII (BDI-II) to survey students from secondary and high schools in Hue province, Vietnam. First, socialdemographic items were introduced in the questionnaire. Vietnamese secondary and high school students' perception of depression differs concerning gender and grade measured by BDI-II. BDI-II validated using college students, adult psychiatric outpatients, and adolescent psychiatric outpatients (44). The participants' responses are provided in five different levels based on a 4-point scale indicates the degree of severity; items are rated from 0 (not at all) to 3 (an extreme form of each symptom).

\section{Analyses}

All participants were provided informed consent before participation and receiving an explanation of the purpose of the research. The ethics committee approved the research of Hue University, Vietnam. The Statistical Package for the Social Sciences (SPSS) version 20 was used for data analyses. The coding procedure was performed as follow: $0=$ Not at all, 1 = Mildly - It did not bother me much, 2 = Moderately - It was very unpleasant, but I could stand it, 3 = Severely - I could barely stand it $(44,45)$. According to Beck, Steer (44) and Smarr (45), the following guidelines have been suggested to interpret the BDI-II, Minimal range 0-13; Mild depression 1419; Moderate depression 20- 28; Severe depression 2963.

\section{Ethical approval}

The study protocol was approved by the Department of Psychology and Education, University of Education, Hue University, Thua Thien Hue Province, Vietnam (No. 680/QĐ-ĐHSP).

\section{Results}

The levels of depression are presented in Table 2. The below table showed that the highest rate of depression was minimal depression $(50.7 \%)$ with more than half of the students scoring under 14 points and the lowest rate was severe depression (7.7\%) with 103 students scoring 20-28 points. The proportion of mild depression was $22.8 \%$ of the students in which the cases with moderate depression had $22,8 \%$.

Table 2. Percentage of the adolescents' depressive disorders in Hue City

\section{\begin{tabular}{|l|l|l|}
\hline The levels of depression & n & $\%$ \\
\hline
\end{tabular}}

\begin{tabular}{|l|l|l} 
Minimal range 0-13 & 678 & 50.7
\end{tabular}

\begin{tabular}{l|l|l}
\hline Mild depression 14-19 & 305 & 22.8
\end{tabular}

\begin{tabular}{|l|l|l|}
\hline Moderate depression 20-28 & 223 & 16.7
\end{tabular}

\begin{tabular}{l|l|l}
\hline Severe depression 29-63 & 130 & 9.7
\end{tabular}

Note: $n$ : Number of participants; \%: Percentage

From the below table, we find a Chi-square test of independence was calculated comparing the frequency of depression academic performance. A significant interaction was found $\left(\chi^{2}(12)=65.970, p<\right.$ $.05)$. Good students were more likely to increase depression than the others.

Table 3. Percentage of depressive disorder in terms of academic performance

\begin{tabular}{|c|c|c|c|c|c|c|c|c|c|c|c|c|c|c|c|}
\hline \multirow{4}{*}{ Level } & \multirow{4}{*}{ Total } & \multirow{2}{*}{\multicolumn{10}{|c|}{ Academic performance }} & \multirow{4}{*}{$\begin{array}{l}\text { Contingency } \\
\text { coefficient }\end{array}$} & \multirow{4}{*}{$\chi^{2}$} & \multirow{4}{*}{ df } & \multirow{4}{*}{$\mathbf{p}$} \\
\hline & & & & & & & & & & & & & & & \\
\hline & & \multicolumn{2}{|c|}{ Poor } & \multicolumn{2}{|c|}{$\begin{array}{l}\text { Below } \\
\text { Average }\end{array}$} & \multicolumn{2}{|c|}{ Average } & \multicolumn{2}{|c|}{ Good } & \multicolumn{2}{|c|}{ Excellent } & & & & \\
\hline & & $\mathrm{n}$ & $\%$ & $\mathrm{n}$ & $\%$ & $\mathrm{n}$ & $\%$ & $\mathrm{n}$ & $\%$ & $\mathrm{n}$ & $\%$ & & & & \\
\hline Minimal range $0-13$ & 678 & 0 & 0 & 10 & 1.5 & 116 & 17.1 & 279 & 41.2 & 273 & 40.3 & \multirow{4}{*}{0.2} & \multirow{4}{*}{65.970} & \multirow{4}{*}{12} & \multirow{4}{*}{0.001} \\
\hline Mild depression 14-19 & 305 & 0 & 0 & 5 & 1.6 & 74 & 24.3 & 123 & 40.3 & 103 & 33.8 & & & & \\
\hline Moderate depression 20-28 & 223 & 0 & 0 & 9 & 4.0 & 59 & 26.5 & 104 & 46.6 & 51 & 22.9 & & & & \\
\hline Severe depression $29-63$ & 130 & 3 & 2.3 & 6 & 4.6 & 28 & 21.5 & 59 & 45.4 & 34 & 26.2 & & & & \\
\hline
\end{tabular}


The below table illustrated that the highest rate in all levels of depression was Good students. Specifically, Good students accounted for $45.4 \%$ in Severe depression, $46.6 \%$ in Moderate depression and $40.3 \%$ in Mild depression. Excellent students accounted for $26.2 \%$ in Severe depression, $22.9 \%$ in Moderate depression and $33.8 \%$ in Mild depression. Poor students had the lowest rate in all levels of depression, with only three students suffering Severe depression (2.9\%). There were 678 students did not suffer depressive symptoms with 273 Excellent students (40.3\%), 279 Good students (41.2\%), 116 Average students (17.1\%) and 10 Below Average students (1.5\%).

Table 4. Percentage of depressive disorder in terms of family structure Family structure

\begin{tabular}{|c|c|c|c|c|c|c|c|c|c|c|c|c|c|}
\hline \multirow[t]{2}{*}{ Level } & \multirow[t]{2}{*}{ Total } & \multicolumn{2}{|c|}{$\begin{array}{l}\text { Two-parent } \\
\text { family }\end{array}$} & \multicolumn{2}{|c|}{$\begin{array}{l}\text { Divorced or } \\
\text { separated } \\
\text { parents }\end{array}$} & \multicolumn{2}{|c|}{$\begin{array}{c}\text { Deceased } \\
\text { father/mother }\end{array}$} & \multicolumn{2}{|c|}{$\begin{array}{l}\text { Another } \\
\text { situation }\end{array}$} & \multirow[t]{2}{*}{$\begin{array}{l}\text { Contingency } \\
\text { coefficient }\end{array}$} & \multirow[t]{2}{*}{$\chi^{2}$} & \multirow[t]{2}{*}{ df } & \multirow[t]{2}{*}{$\mathbf{p}$} \\
\hline & & $\mathrm{n}$ & $\%$ & $\mathrm{n}$ & $\%$ & $\mathrm{n}$ & $\%$ & II & $\%$ & & & & \\
\hline Minimal range $0-13$ & 678 & 620 & 91.4 & 29 & 4.3 & 20 & 2.9 & 9 & 1.3 & \multirow{4}{*}{0.126} & \multirow{4}{*}{21.594} & \multirow{4}{*}{9} & \multirow{4}{*}{0.010} \\
\hline Mild depression 14-19 & 305 & 269 & 88.2 & 18 & 5.9 & 11 & 3.6 & 7 & 2.3 & & & & \\
\hline Moderate depression $20-28$ & 223 & 185 & 83.0 & 19 & 8.5 & 15 & 6.7 & 4 & 1.8 & & & & \\
\hline Severe depression $29-63$ & 130 & 108 & 83.1 & 14 & 10.8 & 4 & 3.1 & 4 & 3.1 & & & & \\
\hline
\end{tabular}

From the above table, we find a Chi-square test of independence was calculated comparing the frequency of depression between family structures. A significant interaction was found $\left(\chi^{2}(9)=21.594, \mathrm{p}<\right.$ $.05)$. Students who had divorced or separated parents were more likely to increase depression gradually than the others. Specifically, students living with divorced or separated parents accounted for $4.3 \%$ in minimal depression, $5.9 \%$ in mild depression, $8.5 \%$ in moderate depression and $10.8 \%$ in severe depression.

It is noticeable that although students from twoparent family accounted for the largest proportion of all levels of depression, this group were more likely to decrease depression gradually compared to the others. Besides, it is clear that students who had deceased father/mother had the lower percentage in all levels of depression compared to those from two-parent family and divorced or separated parents with $2.9 \%$ in minimal depression, $3.6 \%$ in mild depression, $6.7 \%$ in moderate depression and $3.1 \%$ in severe depression. Other situation accounted for the smallest proportion of all levels of depression.

\section{Discussion}

This research examined the relationship between depression, academic performance, and family structure. The main findings indicate that there was a significant interaction between depression and academic performance. Besides, a significant interaction between depression and family structure was also found. Specifically, students with good or excellent academic performance were more likely to increase depression than others. This result brought into light that students with good or excellent academic performance experienced academic pressure from a variety of potential sources. Academic pressure in secondary or high school could be parental pressure $(46,47)$, the rising amount of schoolwork, assignment deadlines or examinations which were documented factors affecting students' mental health and resulted in psychological problems related to disorders such as depression. This finding supports a prior study made by Zhang and et al
(2013), which surveyed $1.2978^{\text {th }}$ and $9^{\text {th }}$-grade students in Shandong, China and concluded that students with more severe academic pressure showed higher levels of depression. Besides, Wenz-Gross and Siperstein (48), also revealed that individuals who have high levels of academic stress are more likely to experience feelings of depression. The findings of Chen and $\mathrm{Li}$ (26) suggested that studying process in school with a large number of assignments, overwhelming contents or difficulties in completing homework required to maintain attention and concentration caused depression in Chinese students. Contrary to our findings, Owens, Stevenson (20) reported that students with higher levels of depression frequently have poorer academic performance. This could be explained by often facing academic concerns like lack of energy, motivation and hopes to study and succeed in the school, a decrease of concentration in studying process of depressed students $(12,13)$.

Our results demonstrated that students who had divorced or separated parents were more likely to increase depression gradually than the others. These findings are in accordance with findings reported by Brubeck and Beer (25), who indicated that high school students from divorced families suffered more depression and had lower grade point averages. The students from divorced families had more adverse experiences in daily life, which caused anxiety, depression and antisocial behaviour (49). Hadžikapetanović, Babić (50) also concluded that parents' divorce is one of the most significant factors for the development of depression. Specifically, adolescents experiencing parental divorce would suffer more depressive symptom. However, Mahon, Yarcheski (51) reported that individuals from divorced family showed no difference in levels of depression compared to those from intact families. Our findings showed that students who had deceased father/mother had a lower percentage in all levels of depression compared to those from a two-parent family.

Contrary to these findings, Sadock and Sadock (41) concluded that the depression rate for students 
living with both parents is significantly lower than other situations such as parents' death or parents' divorce. This means parents' death could be one of the significant risk factors for the development of depression. Moreover, Lloyd (29) indicated that experiencing parental bereavement during childhood increases the risk of depression in adulthood. The limitation of the present studies naturally is the sampling process. The sample was selected randomly from five schools in Thua Thien Hue province, Vietnam.

\section{Conclusion}

Depression is a widespread phenomenon, and one of the most important mental health problems globally documented by children and adolescents. Importantly, our results provide additional information about the relationships between depression and academic performance and family structure. Education in Vietnam transformed into a new form that brings about the education curricula with more complexity of academic content and causes academic pressures, stress, anxiety and depressive symptoms. So that, future studies should aim to replicate results in larger sample size or in other provinces in Vietnam to examine factors influencing on students' depression such as not only academic performance but also academic curricula, parental pressures and academic stress.

\section{References}

1. Spielberger CD. Cross-cultural assessment of emotional states and personality traits. European Psychologist. 2006;11(4):297-303.

2. Neil AL, Christensen H. Efficacy and effectiveness of school-based prevention and early intervention programs for anxiety. Clinical Psychology Review. 2009;29(3):208-215.

3. Sahoo S, Khess CR. Prevalence of depression, anxiety, and stress among young male adults in India: a dimensional and categorical diagnoses-based study. The Journal of Nervous and Mental Disease. 2010;198(12):901-904.

4. Savina E, Coulacoglou C, Sanyal N, Zhang J. The study of externalizing and internalizing behaviours in Greek, Russian, Indian, and Chinese children using the Fairy Tale Test. School Psychology International. 2012;33(1):39-53.

5. Tully PJ, Zajac IT, Venning AJ. The structure of anxiety and depression in a normative sample of younger and older Australian adolescents. Journal of Abnormal Child Psychology. 2009;37(5):717.

6. Sabaté E. Depression in young people and the elderly. Priority medicines for Europe and the world "A public health approach to innovation". WHO. 2004;3-27.

7. Liu X, Guo C, Okawa M, Zhai J, Li Y, Uchiyama M, et al. Behavioral and emotional problems in Chinese children of divorced parents. Journal of The American Academy of Child \& Adolescent Psychiatry. 2000;39(7):896-903.

8. MacPhee AR, Andrews JJ. Risk factors for depression in early adolescence. Adolescence. 2006;41(163):435.
9. Woodgate RL. Living in the shadow of fear: adolescents' lived experience of depression. Journal of Advanced Nursing. 2006;56(3):261-269.

10. Farmer TJ. The experience of major depression: adolescents'perspectives. Issues in Mental Health Nursing. 2002;23(6):567-585.

11. Brent DA. Assessment and treatment of the youthful suicidal patient. Annals of the New York Academy of Sciences. 2001;932(1):106-131.

12. Shaffer D, Waslick B. The many faces of depression in children and adolescents: American Psychiatric Pub; 2008.

13. Sriphet C. Factors influencing adolescent depression: Faculty of Graduate Studies, Mahidol University; 2001.

14. Hysenbegasi A, Hass SL, Rowland CR. The impact of depression on the academic productivity of university students. Journal of mental health policy and economics. Journal of Mental Health Policy and Economics. 2005;8(3):145-151.

15. Wagstaff AE, Polo AJ. Ethnicity and adolescent depression: Prevalence, access to services, and promising interventions. The Prevention Researcher. 2012;19(4):8-11.

16. Hammen C, Rudolph K, Weisz J, Rao U, Burge D. The context of depression in clinic-referred youth: Neglected areas in treatment. Journal of the American Academy of Child \& Adolescent Psychiatry. 1999;38(1):64-71.

17. Vatanasin D, Thapinta D, Thompson EA, Thungjaroenkul P. Testing a Model of Depression Among $\mathrm{T}$ hai Adolescents. Journal of Child and Adolescent Psychiatric Nursing. 2012;25(4):195-206.

18. Khesht-Masjedi MF, Shokrgozar S, Abdollahi E, Habibi B, Asghari T, Ofoghi RS, et al. The relationship between gender, age, anxiety, depression, and academic achievement among teenagers. Journal of Family Medicine and Primary Care. 2019;8(3):799-804.

19. Busari A. Evaluating the relationship between gender, age, depression and academic performance among adolescents. Scholarly Journal of Education. 2012;1(1):6-12.

20. Owens M, Stevenson J, Hadwin JA, Norgate R. Anxiety and depression in academic performance: An exploration of the mediating factors of worry and working memory. School Psychology International. 2012;33(4):433-449.

21. Maurizi LK, Grogan-Kaylor A, Granillo MT, Delva J. The role of social relationships in the association between adolescents' depressive symptoms and academic achievement. Children and Youth Services Review. 2013;35(4):618-625.

22. Shippee ND, Owens TJ. GPA, depression, and drinking: A longitudinal comparison of high school boys and girls. Sociological Perspectives. 2011;54(3):351-376.

23. Lewinsohn PM, Roberts RE, Seeley JR, Rohde P, Gotlib IH, Hops H. Adolescent psychopathology: II. Psychosocial risk factors for depression. Journal of Abnormal Psychology. 1994;103(2):302-315. 
Be Thi Ngoc Nguyen et.al., Depressive disorder in the adolescents in terms of academic performance and family structure

24. Roeser RW, Eccles JS, Sameroff AJ. Academic and emotional functioning in early adolescence: Longitudinal relations, patterns, and prediction by experience in middle school. Development and Psychopathology. 1998;10(2):321-352.

25. Brubeck D, Beer J. Depression, self-esteem, suicide ideation, death anxiety, and GPA in high school students of divorced and nondivorced parents. Psychological Reports. 1992;71(3):755-763.

26. Chen X, Li B-s. Depressed mood in Chinese children: Development significance for social and school adjustment. International Journal of Behavioral Development. 2000;24(4):472-479.

27. Shahar G, Henrich CC, Winokur A, Blatt SJ, Kuperminc GP, Leadbeater BJ. Self-criticism and depressive symptomatology interact to predict middle school academic achievement. Journal of Clinical Psychology. 2006;62(1):147-155.

28. Rodgers B. Pathways between parental divorce and adult depression. Journal of Child Psychology and Psychiatry. 1994;35(7):1289-1308.

29. Lloyd C. Life events and depressive disorder reviewed: I. Events as predisposing factors. Archives of General Psychiatry. 1980;37(5):529-535.

30. Garrison CZ, Schoenbach VJ, Schluchter MD, Kaplan $\mathrm{BH}$. Life events in early adolescence. Journal of the American Academy of Child \& Adolescent Psychiatry. 1987;26(6):865-872.

31. Hetherington EM, Camara KA. Families in transitionThe processes of dissolution and reconstitution. Review of Child Development Research. 1984;7:398-439.

32. Montemayor R. Picking up the pieces: The effects of parental divorce on adolescents with some suggestions for school-based intervention programs. The Journal of Early Adolescence. 1984;4(4):289-314.

33. Openshaw DK, Thomas DL. The adolescent self and the family. Adolescents in Families. 1986:104-129.

34. Bakker MP, Ormel J, Verhulst FC, Oldehinkel AJ. Childhood family instability and mental health problems during late adolescence: A test of two mediation models-The TRAILS study. Journal of Clinical Child \& Adolescent Psychology. 2012;41(2):166-176.

35. Mäkikyrö T, Sauvola A, Moring J, Veijola J, Nieminen P, JÄRVELIN MR, et al. Hospital-treated psychiatric disorders in adults with a single-parent and twoparent family background: a 28-year follow-up of the 1966 Northern Finland birth cohort. Family Process. 1998;37(3):335-344.

36. O'Connor TG, Thorpe K, Dunn J, Golding J. Parental divorce and adjustment in adulthood: Findings from a community sample. Journal of Child Psychology and Psychiatry. 1999;40(5):777-789.

37. Waldfogel J, Craigie T-A, Brooks-Gunn J. Fragile families and child wellbeing. The Future of Children. 2010;20(2):87-112.
38. Zeiders KH, Roosa MW, Tein JY. Family structure and family processes in Mexican-American families. Family Process. 2011;50(1):77-91.

39. Feldman SS, Rubenstein JL, Rubin C. Depressive affect and restraint in early adolescents: Relationships with family structure, family process and friendship support. The Journal of Early Adolescence. 1988;8(3):279-296.

40. Laukkanen M, Hakko H, Riipinen P, Riala K. Does family structure play a role in depression in adolescents admitted to psychiatric inpatient Care? Child Psychiatry \& Human Development. 2016;47(6):918-924.

41. Sadock BJ, Sadock VA. Kaplan and Sadock's pocket handbook of clinical psychiatry: Lippincott Williams \& Wilkins; 2010.

42. Huynh VS, Tran-Chi V-L. Vietnamese High School Students' Perceptions of Academic Advising. International Journal of Learning, Teaching and Educational Research. 2019;18(8):98-107.

43. Dillman DA. Mail and Internet surveys: The tailored design method. New York: John Wiley \& Sons; 2000.

44. Beck A, Steer R, Brow G. Manual for the Beck Depression Inventory-II. San Antonio, United States: The Psychological Corporation; 1996.

45. Smarr KL. Measures of depression and depressive symptoms: The Beck Depression Inventory (BDI), Center for Epidemiological Studies-Depression Scale (CES-D), Geriatric Depression Scale (GDS), Hospital Anxiety and Depression Scale (HADS), and Primary Care Evaluation of Mental Disorders-Mood Module (PRIME-MD). Arthritis Care \& Research: Official Journal of the American College of Rheumatology. 2003;49(S5):S134-S46.

46. Deb S, Strodl E, Sun J. Academic stress, parental pressure, anxiety and mental health among Indian high school students. International Journal of Psychology and Behavioral Sciences. 2015;5(1):26-34.

47. Lee MT, Wong BP, Chow BW-Y, McBride-Chang C. Predictors of suicide ideation and depression in Hong Kong adolescents: Perceptions of academic and family climates. Suicide and Life-threatening Behavior. 2006;36(1):82-96.

48. Wenz-Gross M, Siperstein GN. Importance of social support in the adjustment of children with learning problems. Exceptional Children. 1997;63(2):183-193.

49. Strohschein L. Parental divorce and child mental health trajectories. Journal of Marriage and Family. 2005;67(5):1286-1300.

50. Hadžikapetanović $H$, Babić T, Bjelošević E. Depression and intimate relationships of adolescents from divorced families. Medicinski Glasnik. 2017;14(1):854-916.

51. Mahon NE, Yarcheski A, Yarcheski T. Anger, anxiety, and depressionin early adolescents from intact and divorced families. Journal of Pediatric Nursing. 2003;18(4):267-277. 